\title{
CLINICAL STUDIES ON INCOORDINATION OF THE CIRCULATION, AS DETERMINED BY THE RESPONSE TO ARISING ${ }^{1}$
}

\author{
BY ISAAC STARR \\ (From the Research Department of Therapeutics, and the Medical Division of the Hospital \\ of the University of Pennsylvania, Philadelphia)
}

(Received for publication March 11, 1943)

Diseases of the heart and circulation have often been divided into the organic and the functional. In the former, characteristic lesions are found at necropsy; in the latter, such lesions are lacking. Thus, the diagnosis of "functional" diseases has been a negative one; the patients suffered from certain symptoms but no organic lesions could be demonstrated. As long as interest in structural pathology dominated clinical medicine, doctors were content with this classification, but to physicians endowed with physiological interest, these "functional" conditions present a challenge; have these patients a real abnormality or are they imagining their symptoms?

Both my interest in this subject and the beginning of this investigation antedated the war by several years, but there is especial point to such a study in wartime, for experience has shown that patients with "functional" abnormalities of the circulatory apparatus are not equal to the rigors of military life. Therefore, objective methods for their detection are of special importance.

In planning this study, I was much influenced by an analogy with the usual clinical investigation of neuromuscular mechanisms. A muscle may be strong or weak, but irrespective of its strength, the movements may be incoordinate; the latter abnormality is demonstrated by assigning a familiar task like touching the nose with the finger tip and observing the nicety with which the movement is performed. One may think of the circulation in a similar fashion. Evidence has been presented that the circulation of resting subjects may be normal, above normal, or below (1), but there have been almost no data concerning its coordination, that is, the patient's ability to adapt the flow of blood to the performance of a task. The purpose of this investigation was to supply a simple test for such circulatory coordination and

1 This work was assisted by grants from the Penrose and Daland Funds of the American Philosophical Society. explore the clinical field by means of it. We have, therefore, devised a test, similar in design to that used to detect muscular incoordination, i.e., a familiar demand is made on the circulation by having the subject, after lying recumbent for 15 minutes, arise and stand upright. The assumption of the upright position requires complicated circulatory adjustments to prevent the blood from pooling in the lower portions of the body and to maintain the circulation to the brain. The nicety of circulatory adaptation to this task can be studied by observing the changes in cardiac output and blood pressure which follow the change of position.

The clinical literature abounds with comparisons of the blood pressure and pulse rate in the erect and recumbent positions and the method of testing which we used was quite similar to that of Crampton (2) and to the first part of Schneider's fitness test (3), except for the use of the ballistocardiographs. By employing these instruments to estimate the amount of the circulation, in addition to the more familiar measurements, we hoped and expected to advance rapidly the knowledge of the circulatory abnormalities to be found in sick persons.

Normal standards have been secured by making 120 tests on 75 healthy persons, while abnormalities have been sought by about 200 tests on 150 ambulatory patients. Indeed, it soon proved that circulatory incoordination was common in many conditions of disease.

\section{METHODS}

Selection of subjects

The healthy persons tested were all young adults; they were chiefly medical students, hospital technicians, and stenographers. A few subjects, about to receive drug injections in class demonstrations, were excited when the test was made. The sexes were approximately equal in number.

The patients studied were drawn from the wards, and, 


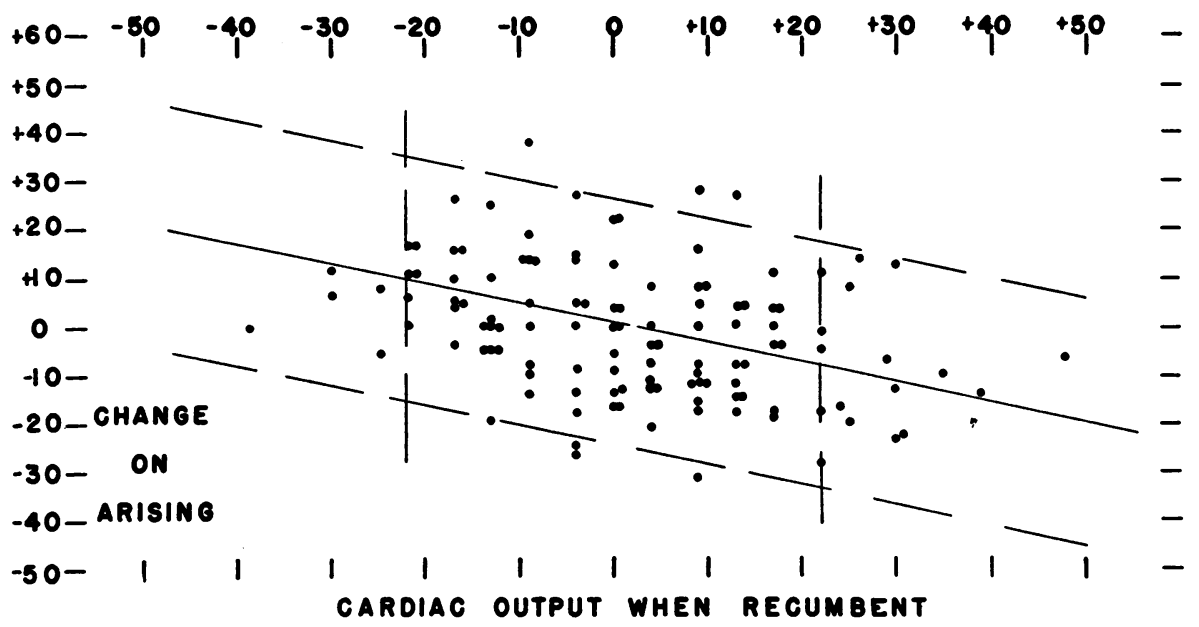

Fig. 1. Normal Standards from Results Obtained on Healthy Persons

Abscissa: Cardiac output per minute when recumbent, expressed in percentage deviation from the expected normal. The vertical broken lines indicate the accepted normal limits for resting subjects, derived from other data (6).

Ordinate: Change in the cardiac output per minute after arising, expressed as a percentage of the recumbent value. The slanting solid line is the calculated best line for the data (regression $\mathbf{y}$ on $\mathbf{x}$ ). The slanting broken lines are placed at a distance of twice the standard deviation about the regression and they constitute the usual statistical limits of normality for the change of the circulation on arising.

to a lesser extent, from the Out-Patient Department of the University Hospital. Many patients who were weak, and this includes the great majority of bed patients, could not stand without enough muscular movement to ruin the "V" ballistic record, so those whose cardiac output is reported numerically were almost all ambulatory cases.

\section{Technique of tests}

The subjects were never examined within 2 hours after a meal. They lay at rest on the horizontal (" $\mathrm{H}$ ") ballistocardiograph (4) for 15 minutes, blood pressure being taken towards the end of this period. Immediately after taking the " $\mathrm{H}$ " ballistocardiogram, the subjects arose, walked 3 paces to the vertical ("V") ballistocardiograph (5), which stood at the foot of the " $\mathrm{H}$ " instrument, and stepped up $8 \frac{1}{2}$ inches to its platform. The " $\mathrm{V}$ " ballistocardiogram was taken between 1 and 3 minutes after the subject took his stance. Blood pressure was taken immediately before or after the "V" ballistocardiogram. Cardiac output was calculated by the area method (6).2

2 A mathematical error has been detected in this paper (6). Giving directions for calculating cardiac output from records secured from ballistocardiographs with a calibration different from ours, we said (p. 438), "If 280 grams displaces the light spot image $2 \mathrm{~cm}$. the estimations of cardiac output from our formulae must be halved." Since, in our apparatus, 280 grams displaces the image $1 \mathrm{~cm}$., inspection of our formulae shows the error at once. The value to be halved is not the cardiac output, but the
For routine clinical purposes, the " $\mathrm{H}$ " ballistocardiogram is more satisfactory than the "V," for the latter is much more subject to distortion from movements of the patient. In our patients, such movements often ruined the record for short periods and sometimes so overwhelmed it that the cardiac complexes could hardly be identified. Examples of such distorted records are given in Figure 3. With a single exception there described, unless a good series of normal complexes was recorded, the calculation of cardiac output was never attempted.

\section{RESULTS}

\section{Normal standards}

The results obtained on the first 56 normal subjects have been published (5), the average change of the circulation on arising was +1 per cent and the standard deviation about this mean was 14 per cent. Therefore, in healthy persons, the average circulation is maintained on arising, and indi-

altitudes of the waves as measured on the record. The former being derived from the square root of the latter. our statement is obviously erroneous.

As we have always adjusted our ballistocardiographs to the same calibration, the erroneous correction was never used, and so the error was not discovered for some time. For the same reason, the results given in our papers do not need correction. 
vidual subjects whose change of circulation falls between +29 per cent and -27 per cent can be considered normal.

However, the discovery of a trend within the normal group permits a more exact definition of the normal response. In persons whose " $\mathrm{H}$ " circulation is in the upper half of the normal range, the circulation tends to diminish when they arise; in those with " $\mathrm{H}$ " circulation in the lower half, it tends to increase. To make use of this discovery, the results obtained more recently were added to those published before (5), making a total of 120 estimations on healthy persons, and the result of statistical analysis is given in Figure 1. The normal limits may now be defined as the zone shown in Figure 1 and we have not hesitated to extrapolate it into territory not encountered in normal subjects.

\section{Consistency}

The results of repeated estimations of the change of the circulation on arising, obtained on 20 normal persons, have been published (5). In 34 instances, one can compare results obtained on one day with those found when the same subject was tested on a later day; the difference between such duplicates averaged 11.7 per cent.

A corresponding figure for patients can also be obtained, for 2 or more tests have been performed on 27 patients at intervals of a day or more. But the clinical conditions often changed so much during the interval that many of the tests could not be called duplicates. In only 10 of the patients with incoordinate circulations were clinical conditions relatively constant, and in these, the difference between the duplicates averaged 22 per cent, which is significantly larger than the corresponding value for normal persons. Evidently persons with incoordinate circulations do not give as consistent results as do the healthy, and since their abnormality is one of regulation this is not surprising.

Because of this large deviation of duplicates in our patients, we studied the consistency of our interpretation of the response of the circulation to arising. The results of 15 tests, made at intervals of 1 to 2 days, on a patient with syphilitic aortic regurgitation were all judged normal. The results of 3 tests, made on a patient with angio- neurotic edema, were all judged abnormal. A similar consistency was found in $\mathbf{1 5}$ other patients.

On the other hand, repetition of the test sometimes indicated that the status had changed. Sympathectomy made 2 cases incoordinate, as will be described. At times, circulatory coordination returned to normal as the patient's condition improved. This occurred once as a patient with rheumatic heart disease recovered from failure, and again as a patient with hypertension improved with rest in bed. One patient was improved by an abdominal binder, another became normal when benzedrine was omitted. Variable results were found in a case of myxedema receiving thyroid and in a severe diabetic receiving large doses of insulin. But as a rule, unless some obvious disturbing factor was present, when circulatory coordination was judged normal or abnormal on the first test, later tests did not alter this judgment. Our test is obviously a crude one but it suffices to divide the normal from the abnormal.

\section{Results in clinical conditions}

Table I gives the clinical data on those patients judged to have incoordination of the circulation. The results obtained in these cases, as well as in patients with normal coordination, are given in Figure 2. Inspection of this figure shows that incoordination of the circulation may be subdivided into 2 types. In the type found most commonly, the circulation after arising is abnormally increased. In the much rarer type, the circulation after arising is abnormally diminished. For convenience of expression, these 2 types will be spoken of as incoordination "upward" and "downward," respectively.

The results charted in Figure 2 show that incoordination of the circulation is found frequently in heart disease and that its presence or absence is not dependent on any particular etiology of the cardiac lesion. About half the cases tested were abnormal. Although the incoordination was more frequently upward, it is of interest that the great majority of the cases of incoordination downward were found in this group.

All the 23 cases included under the heading hypertension had blood pressures usually over 150 $\mathrm{mm}$. $\mathrm{Hg}$ systolic or $100 \mathrm{~mm}$. $\mathrm{Hg}$ diastolic, or both, when recumbent. Only one was a case of chronic 


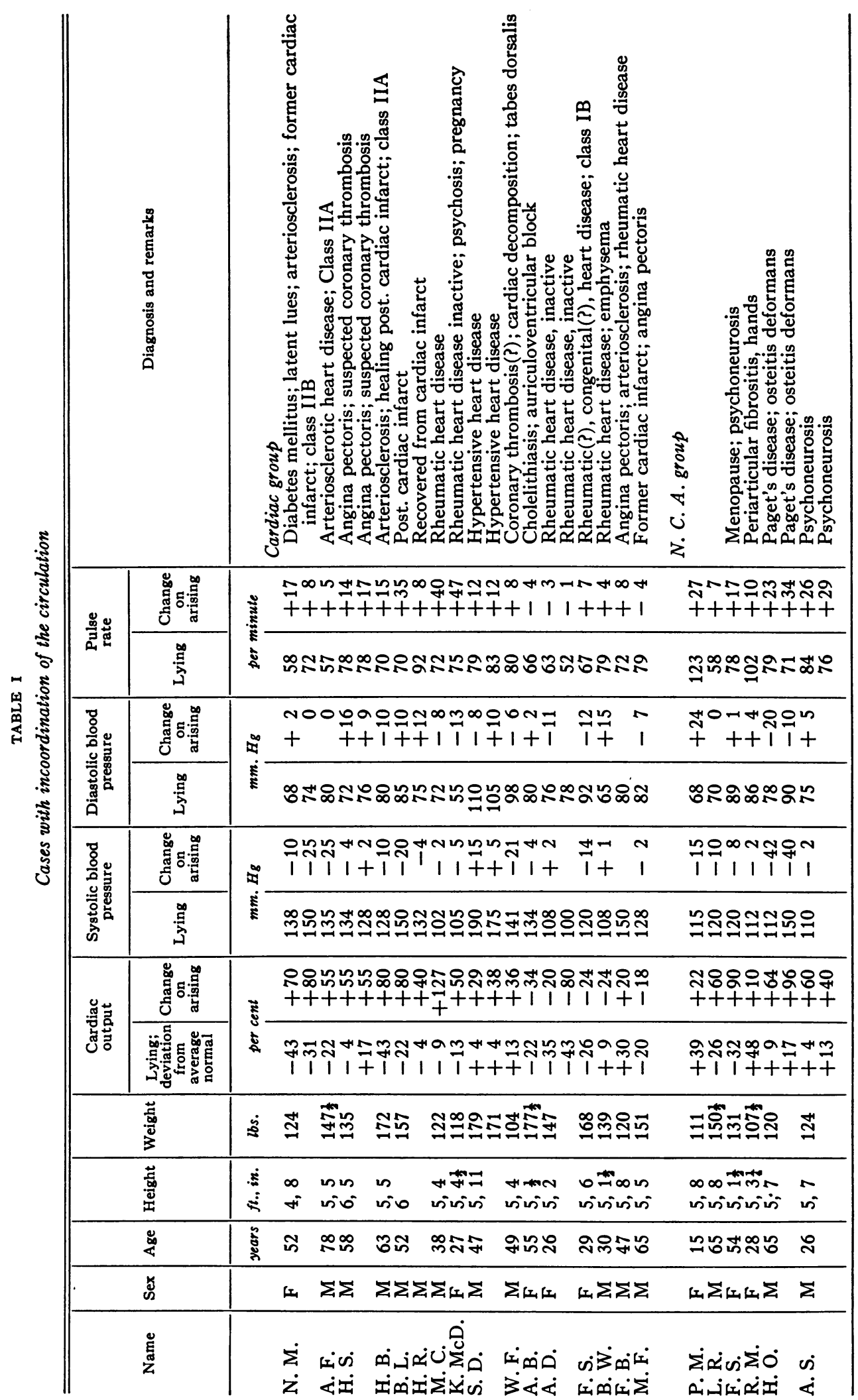




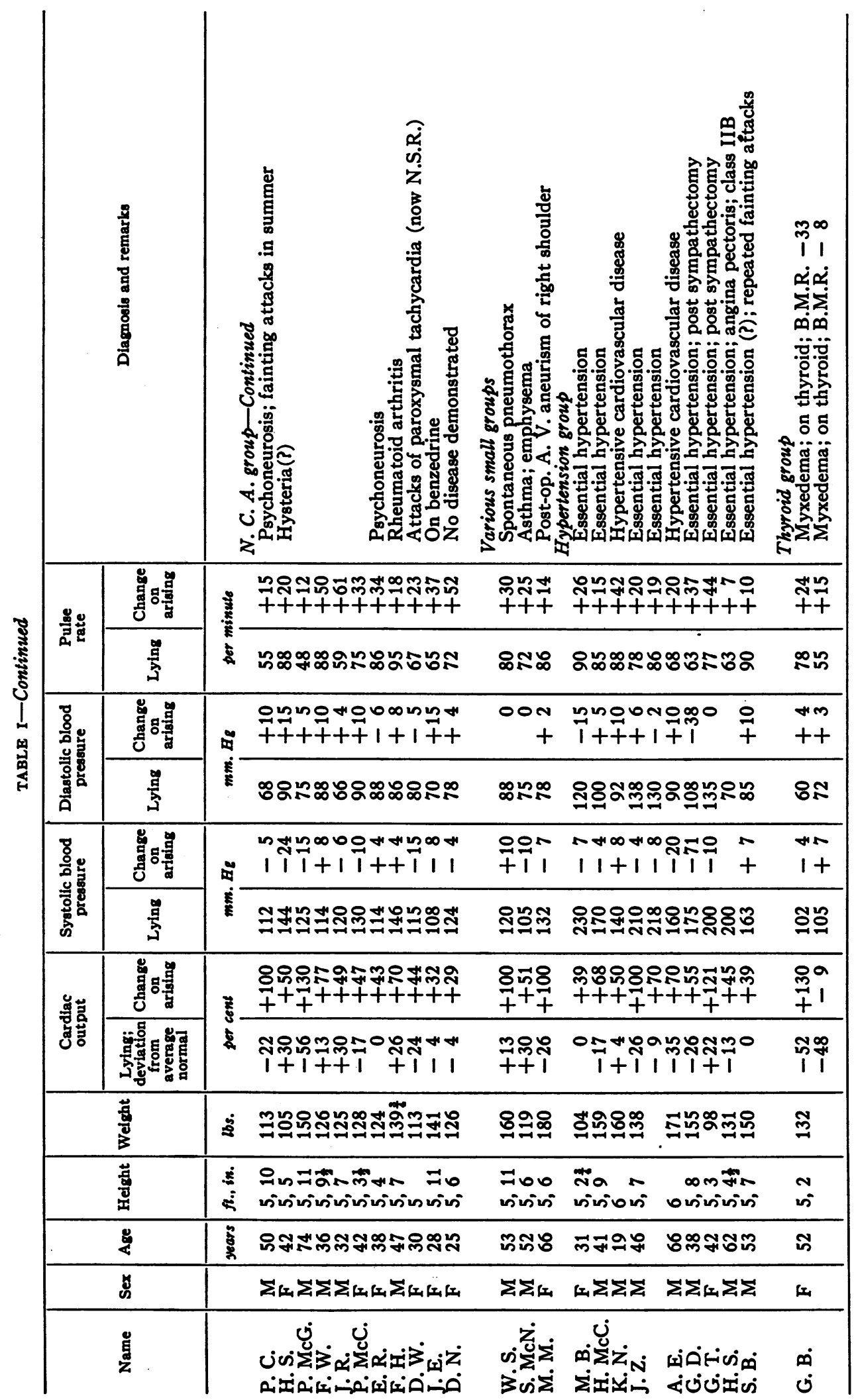




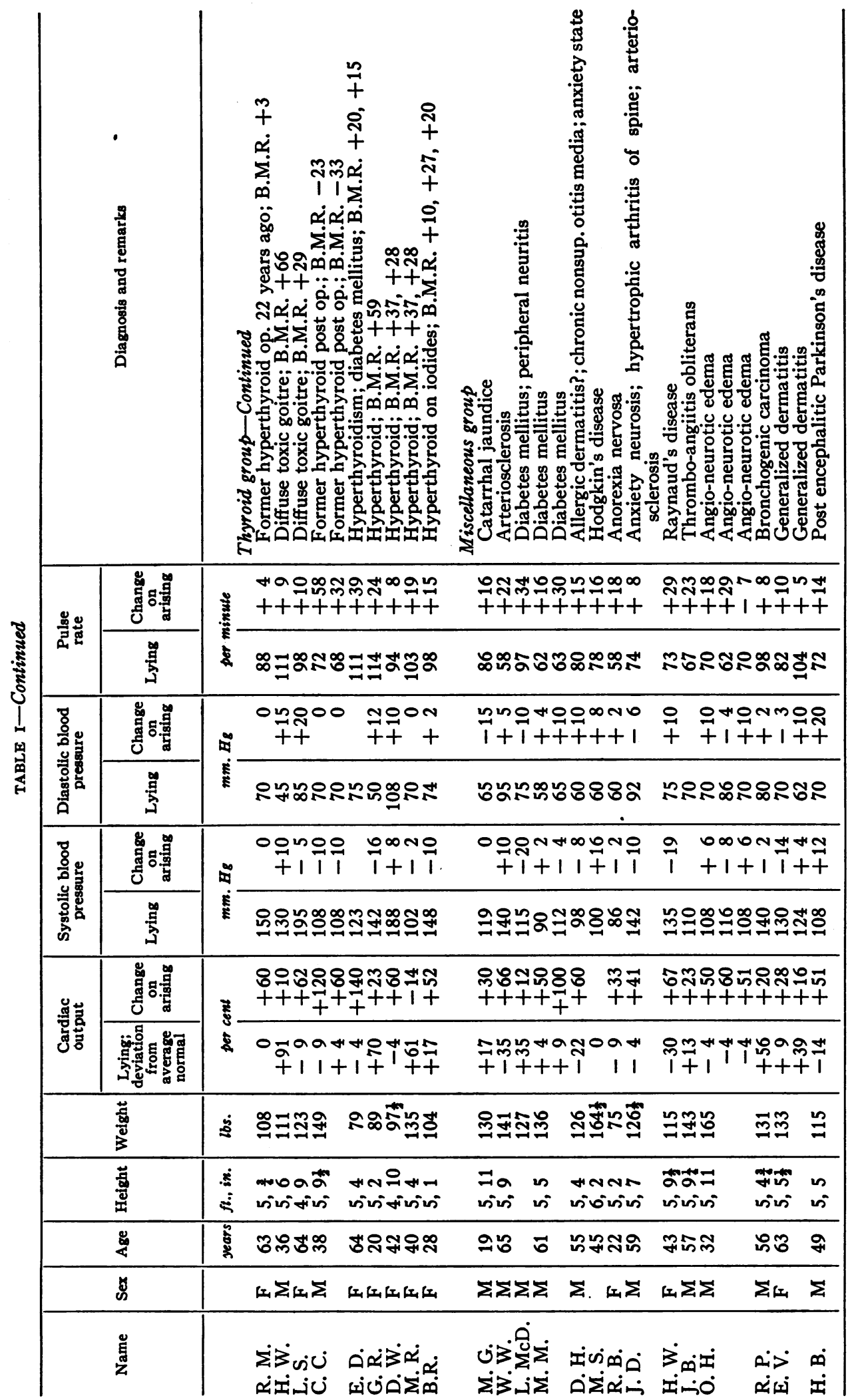




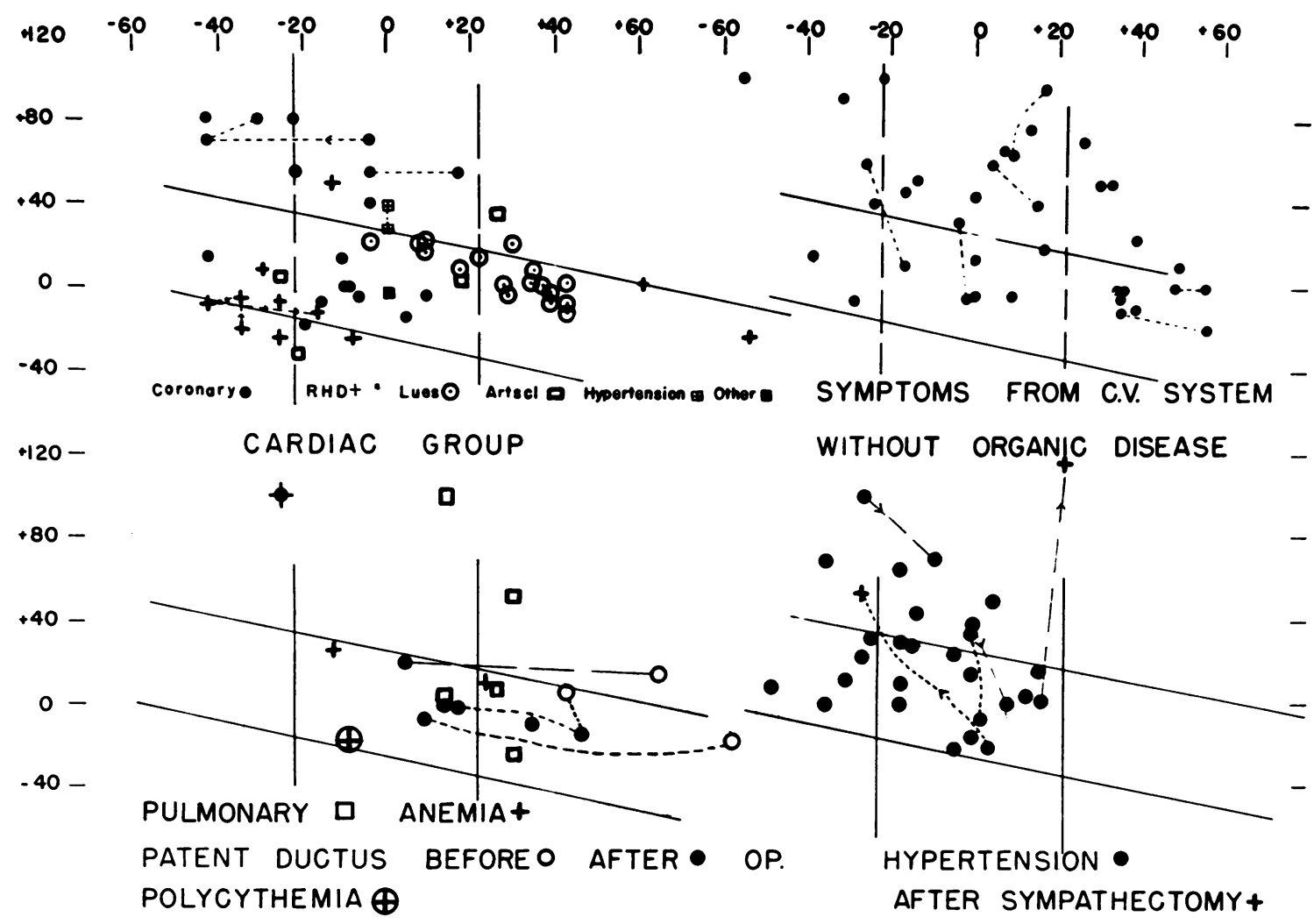

$+160-$

$+120-$<smiles>C1CO1</smiles>

$+80-$<smiles>[I-][Tl]</smiles>

$+40-$

o-

$-40-$

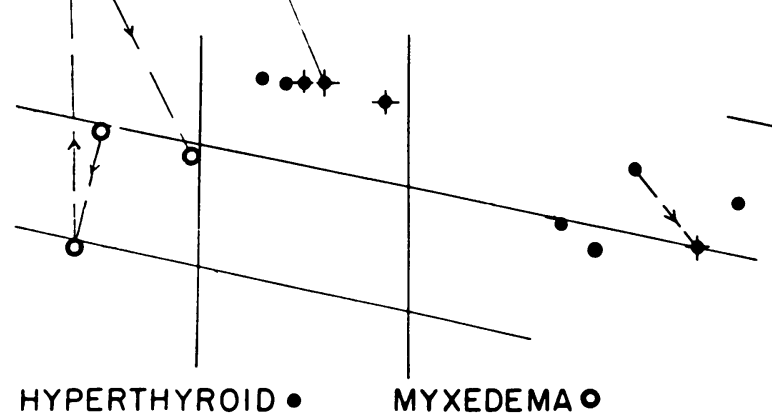

FORMER HYPER, NORMAL B.M.R

MISCELLANEOUS

Fig. 2. Results Obtained on Patients

Ordinates and abscissae are the same as in Figure 1. The horizontal broken lines define the normal limits of the resting cardiac output, the slanting solid lines define the normal limits of the change on arising. Only values found within the parallelogram are normal in both respects.

The results of multiple tests on the same subject are connected by lines, except when the dots are already touching, and in the case of a patient with syphilitic heart disease, tested 15 times. In the figure at the upper left, all the dotted circles between the slanting lines pertain to this one patient. The one value without these lines belongs to another patient. 

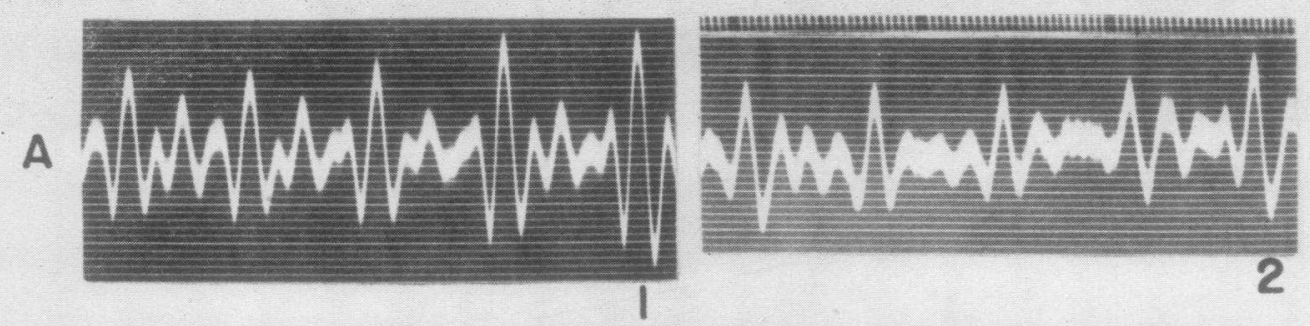

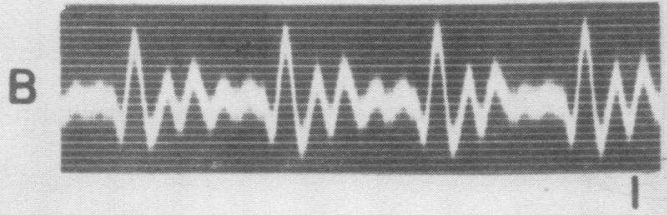

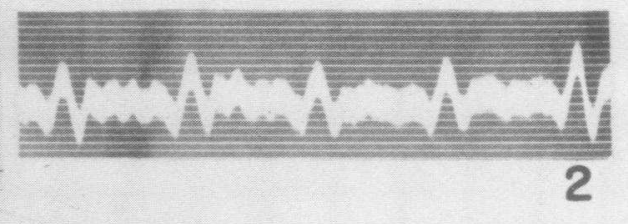

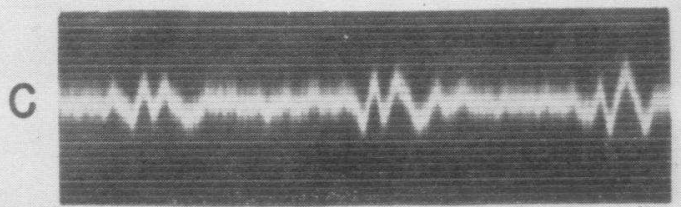
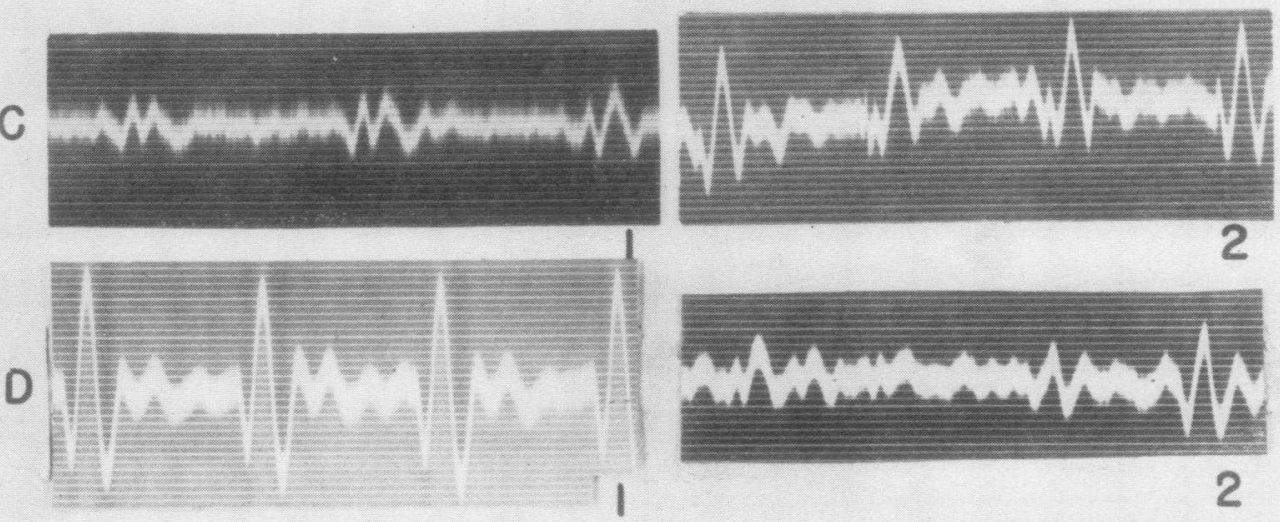

।

2

E
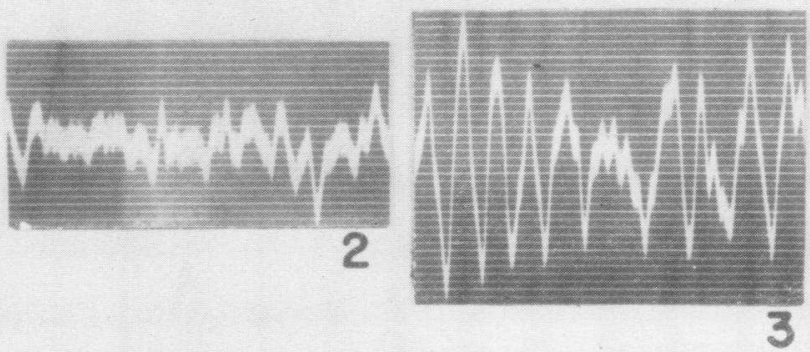

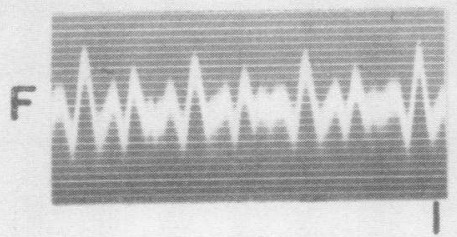
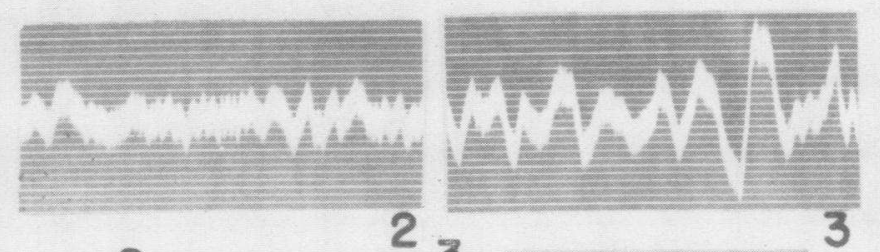

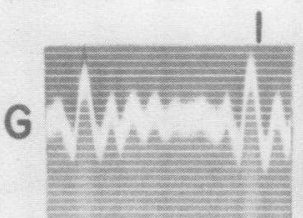
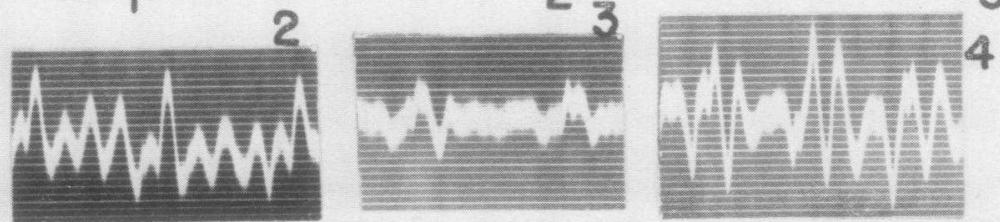

FIG. 3. See opposite page for legend 
glomerular nephritis; the others were diagnosed essential hypertension. None of the cases in this group had any signs or symptoms of cardiac failure or angina pectoris, the only positive signs of cardiac abnormality being enlargement of the silhouette, identified by the orthodiagraph in several instances noted in Table I.

About one third of these cases showed abnormal coordination, always upward, as is shown in Figure 2. This abnormality had no obvious relation to the height of the blood pressure, both normal and incoordinate circulations being found in those whose blood pressure was but little over the normal, as well as in those whose systolic pressures were well over $220 \mathrm{~mm}$. $\mathrm{Hg}$.

Interesting results were secured on the 2 patients tested before and after bilateral sympathectomy, from the sixth thoracic to the second lumbar in one, and from the tenth thoracic to the second lumbar in the other. The circulation of

Fig. 3. Ballistocardiograms Obtained from NorMal Subjects aNd from Patients, after Resting for 15 MinUtes Horizontal ("H") AND then AFTER ARISING AND Standing From 1 To $2 \frac{1}{2}$ MinUtes ("V")

The records are reproduced $\% 6$ their actual size. The time record over A 2 applies to all records; its longest interval is 1 second.

A : Records of Sta., age 46 years, ht. 6 ft., wt. 185 lbs. A normal man. 1, " $\mathrm{H}$," the circulation deviates from expected normal by +22 per cent (normal limits \pm 22 per cent). 2, "V," the change on arising is -11 per cent, a normal response.

B : MM, 19 years, 5 ft., 105 lbs. A normal woman. " $\mathrm{H} "=+9$ per cent, the change on arising -12 per cent, a normal response.

C: P. McG., 74 years, 5 ft. 11, 150 lbs. Chief complaint, poor vision, marked dizziness in the upright position. Physical examination: traumatic cataract, O. D.; retinal detachment, tumor of orbit, O.S. " $\mathrm{H}$ " circulation - 56 per cent, blood pressure 125/75. "V," blood pressure $110 / 80$ change in circulation on arising +130 per cent, an abnormal response.

D: K. E., 32 years, 5 ft. 8, 170 lbs. This subject had no abnormality demonstrated by physical examination, orthodiagram, or electrocardiogram. He had no symptoms whatever at the time of test. In the past, he had suffered from 2 brief attacks of irregular heart action, the second demonstrated to have been auricular fibrillation by electrocardiograph. " $\mathrm{H}$ " circulation -9 per cent, blood pressure 120/80; "V," blood pressure 110/96; change of circulation on arising -30 per cent, an abnormal response.

E: W. L., 45 years, 5 ft. 8, 175 lbs. Postural hypotension. For full description see (7). 1, at rest, blood both these patients was normal before the operation; incoordinate afterwards. In one, this incoordination was accompanied by a marked postural shift in blood pressure, a marked hypertension when recumbent contrasting with a normal blood pressure when standing. In the other, whose record is shown in Figure 3, hypertension persisted in both positions, despite the operation. In contrast to these results, a unilateral cervical sympathectomy, performed to relieve a patient with Raynaud's syndrome, was followed by improvement in circulatory coordination. Obviously, it is the innervation of the vessels in the lower parts of the body which is of major importance in the response to arising.

Patients with unusual hypotension have not been separated into a special group. Nine of the miscellaneous group had systolic pressures of 100 or less when recumbent and 4 of these lacked coordination of the circulation. The lowest blood pres-

pressure $115 / 84$, circulation -30 per cent. 2,10 seconds after taking his stance, no systolic complexes can be positively identified. $\mathrm{He}$ began to feel groggy after 20 seconds standing. 3 , after 40 seconds standing, record destroyed by the muscular movements. Blood pressure was not taken at the end of this experiment but in many similar experiments it averaged about $60 / 40$ at this time. After 3 had been taken, the subject was forced to sit down.

F : L. B., 10 years, 4 ft. 7, 52 lbs. Congenital cavernous hemangioma of left leg and thigh. 1, "H," blood pressure 100/50. 2, 90 seconds after arising, systolic impacts small and hard to identify, blood pressure $100 / 70$. 3, 2 minutes after arising, muscular movements destroy the record, blood pressure $80 / 70$. At $2 \frac{1}{2}$ minutes after arising, the patient was too dizzy to continue standing.

G: L. T., 42 years, 5 ft. 3, 98 lbs. Malignant hypertension. 1 and 2 before operation. 1 , "H," blood pressure $186 / 120$, circulation +17 per cent. 2 , "V," blood pressure 190/130, change on arising 0 per cent. 3 and 4, post-op. 3, "H," blood pressure 200/135. This ballistocardiogram is abnormal in form, the $\mathrm{J}$ peak being retarded, notched, or flattened, so the circulation can be estimated with less confidence, our result +22 per cent. 4, "V," blood pressure 190/135. The ballistic form is again abnormal. The $\mathrm{J}$ peak is normal only in the largest complexes of the respiratory cycle; elsewhere it is notched, and again our estimate of the circulation is uncertain. We calculate the change on arising to be about +120 per cent. The difference between records 3 and 4 is so great we do not hesitate to pronounce this circulation incoordinate, in spite of uncertainties in giving an exact figure. 
sure encountered, $86 / 60 \mathrm{~mm}$. Hg recumbent, and $84 / 62$ standing, was found in a patient with anorexia nervosa whose circulation was incoordinate; but another patient, with a blood pressure of only $90 / 75$ recumbent and 90/80 standing, denied all symptoms and had a well-coordinated circulation. The hospital study disclosed nothing else abnormal in this case.

All the 10 cases included in the thyroid group had had elevated basal metabolic rates, but, as indicated in Table I, some of these had received treatment so this rate was not always elevated when the tests were made. It is of interest that all but 1 of the group had circulations either on the border line or definitely incoordinate, irrespective of the metabolic rate at the time they were tested. In active cases of hyperthyroidism without cardiac involvement, hyperkinemia (8) is the rule; it was accompanied by incoordination in many of the cases we tested. But even after the basal metabolic rate had fallen to normal, or when, because of complicating cardiovascular disease, the circulation had remained within normal limits despite the increased metabolic rate, incoordination was present in all our cases. This abnormality is apparently very characteristic of the abnormal physiology of thyrotoxicosis.

The 1 case of myxedema was tested 4 times, before and during the administration of thyroid. When first tested on September 18th, her basal metabolic rate was -37 per cent and she had marked hypokinemia (9), but coordination was normal. Twelve days later, the administration of thyroid having been started, the patient began to suffer from attacks of substernal pain to the alarm of the attending physicians. At this time, with a B.M.R. of -33 per cent, she was still hypokinemic and also suffered from circulatory incoordination "downward," like certain other cardiac cases. After another month of therapy, the attacks of substernal pain disappeared, the B.M.R. was then -8 per cent, although marked hypokinemia persisted. At this time, the incoordination was "upward," as found in cases of hyperthyroidism. After 3 more months of therapy, clinical improvement was extraordinary; she looked like a different woman, had a resting circulation just at the lower normal limit, and had regained circulatory coordination.
In the pulmonary group were included 2 patients recovering from spontaneous pneumothorax, a coal miner with marked emphysema, a chronic asthmatic, and 1 patient tested several months after a right pneumonectomy for carcinoma. Incoordination was found in the asthmatic and in 1 of the cases of pneumothorax.

The 2 cases of anemia tested, one attributed to iron deficiency and the other to bleeding hemorrhoids, had hemoglobins of 40 per cent and 58 per cent, respectively. The single case of polycythemia examined had a hemoglobin of 140 per cent with 9.4 million red blood corpuscles. The circulation was well coordinated in all these cases.

Circulatory coordination was always normal in the 5 cases of patent ductus arteriosis, 2 of which were tested before and after successful ligation. But a patient with a large post traumatic arteriovenous anastomosis of the right shoulder, recently closed at operation, showed incoordination of the circulation.

In assembling the group of 29 cases entitled neurocirculatory asthenia, we aimed to include only those persons who had symptoms referable to their circulation, such as undue dyspnea or palpitation on exertion, precordial pain not suggestive of angina pectoris, and attacks of dizziness or actual fainting; often accompanied by weakness, nervousness, and undue fatigue; without any evidence of organic disease. We did, however, include a few persons with abnormalities which seemed irrelevant to the circulation and these are stated in Table I.

Inspection of Figure 2 shows at once that the majority of these cases had circulations that were incoordinate; in only 10 cases are the values always found between the slanting lines. Most of these 10 cases had abnormal circulations at rest, leaving only 4 of the 29 in whom our techniques failed to detect some type of abnormality of the circulation. Each of these 4 patients seemed to be suffering from a neurosis. In one, the symptoms dated from a medical examination at which a doctor insisted that the patient had heart disease. Another patient probably misinterpreted normal sensations, as palpitation on exercise or excitement was her only complaint. The other 2 were life-long sufferers from a multitude of other symptoms, as well as those referable to the 
circulation, and no organic basis had ever been discovered.

The 45 subjects not classified into the above groups are given the heading miscellaneous in Figure 2. Incoordinate circulations were found in 13 of these cases. One, a case of angioneurotic edema, was tested 3 times, once during and twice between edematous episodes, his circulation always being incoordinate. It is interesting that 4 cases of advanced arteriosclerosis showed this abnormality; 2 of these had senile psychoses, another was a case of arteriosclerotic peripheral vascular disease. A patient with generalized chronic dermatitis, the skin everywhere being bright red and inflamed, showed circulatory incoordination on each of 2 tests, 8 months apart. Other instances, not needing special comment, are to be found in Table I.

Those with normal circulatory coordination included 5 cases of psychoneurosis, 2 of epilepsy, 2 of catarrhal jaundice, 1 each of Ménière's syndrome, diabetes mellitus, simple goiter, vitamin B deficiency, advanced arteriosclerosis, lymphatic leukemia, congenital lues, migraine, pulmonary tuberculosis, renal calculus, gall bladder diseases, gall stones, and a case of unexplained edema of the feet.

\section{Special cases}

Three patients subject to fainting attacks 'were specially studied and selected parts of the records are shown in Figure 3. The results are not included in the data of Figure 2 or Table I and they deserve special discussion because of the light they throw on the abnormal response to arising.

The first, W. L., was a typical case of postural hypotension and the clinical findings have been reported in detail (7). This patient had been subjected to an elaborate study of postural responses (7). Ballistocardiograms were secured on 4 occasions several months apart. When he was recumbent, the record was perfectly satisfactory and the circulation was always estimated to be far subnormal, the cardiac output ranging between -30 per cent and -35 per cent, in contrast to normal limits of \pm 22 per cent, while the blood pressure ranged between $138 / 100$ and $115 / 84 \mathrm{~mm} . \mathrm{Hg}$. After arising and standing on the platform of the "V" ballistocardiograph, the blood pressure always fell rapidly, a value of $60 / 40$ was obtained 2 minutes after taking his stance in the second test, and symptoms forced him to sit down within a few minutes. The "V" records, started as soon as he took his stance, were most disappointing, a typical record is shown in Figure 3. In no place could cardiac impacts be certainly identified, although, in a few relatively quiet places, impacts as large as those found when he was horizontal would certainly have been seen. The record was dominated by large irregular waves easily traced to the patient's inability to stand still. Exhorting him to stand quietly brought no improvement, for he himself recognized that he was likely to faint when standing still and so was forced to keep moving about whenever he was upright. Evidently, the muscular movements supported his circulation.

The second patient, O. B., a woman of 56 years also suffered from postural hypotension and the hospital study disclosed no other abnormality. When first seen, she could neither stand nor sit upright without collapsing. She was tested on the ballistocardiograph on 2 days, a week apart.

On the first day, when horizontal, the cardiac output varied from +30 per cent to +4 per cent and the blood pressure from $122 / 97$ to $85 / 70$. She was unable to stand upright more than a minute without collapsing and a "V" ballistocardiogram showed nothing but irregular impacts from the muscular movements. However, when seated on a chair placed on the " $\mathrm{V}$ " ballistocardiograph, satisfactory records could be obtained. Directly after taking her seat the cardiac output was 0 per cent, i.e., it did not deviate from the average normal. After this, blood pressure and cardiac output diminished rapidly; 2 minutes later the former was found to be $45 / 35$. The cardiac output diminished to -35 per cent before increased respiratory efforts and the involuntary movements which preceeded collapse destroyed the record of systolic impacts.

After a week of treatment with vasoconstrictor drugs and constant elevation of the head of the bed, the patient could sit without fainting, although still unable to stand. When recumbent, her cardiac output was -4 per cent and her blood pressure 110/83. When seated on the "V" ballistocardiograph, her cardiac output increased to +26 per cent and this level was maintained for the 8 minutes of the test, despite a blood pressure level of $60 / 50$, found 1,3 , and 7 minutes after taking her seat. She denied all symptoms during this test.

The third patient, L. B., a girl of 9 years, suffered from a huge congenital cavernous hemangioma of one leg, with a hypertrophy which made the affected limb 3 inches longer than the other. This hemangioma had a capacity of over $220 \mathrm{cc}$. according to the estimate of Dr. Norman Freeman who compared the water displacement of the leg when the hemangioma was full and empty. This patient was subject to frequent fainting attacks when she stood upright.

We tested the child on 4 occasions and parts of 1 record are shown in Figure 3. Because of lack of knowledge of the size of the great vessels in children, no absolute value can be given to the circulation but the extent of the change can be calculated. On one occasion, as soon as she reached the platform of the "V" ballistocardiograph, the circulation was found to have accelerated, the pulse 
rate having increased while the individual impacts were about the same size as when she was horizontal. In the other tests, the record was started 1 minute after taking her stance and this phase was not recorded. In these and in some mentioned later in the record, the individual systolic impacts must have become smaller, as they could not be clearly identified. Diaphragmatic impacts appeared next at the time when more vigorous respiratory efforts were observed. Soon thereafter, further record of circulatory impacts was prevented by the disturbance caused by uncontrollable muscular movements. Almost immediately thereafter, the blood pressure was found to be about 50 systolic and the subject became too faint to continue standing.

Binding the abnormal limb improved the child's ability to stand.

A very common experience seems related to the results found in these 3 cases. Patients who are very sick from any cause, or who have been confined to bed, usually yield satisfactory ballistic records when horizontal. But after arising, systolic impacts are recorded for only a few seconds before the record is overwhelmed by disordered impacts from the involuntary muscular movements.

\section{DISCUSSION}

Physiological studies on the vasomotor nerves, performed chiefly in animal experiments, have long provided a background for the understanding of postural responses in clinical conditions. The results reported herein are in accord with the older conceptions.

In healthy persons, the act of arising presents no problem. The required vascular changes are produced at once by a reflex mechanism working through vasomotor nerves. This old conception is supported by our results in the 2 patients subjected to extensive sympathetic thoracico-lumbar ganglionectomy, for, after this procedure, their postural responses became abnormal.

However, in a multitude of conditions of mild ill health, the subjects, on assuming the erect posture, behave as if their vasomotor responses were inadequate, for a second physiological mechanism is brought into play. The increased cardiac output which these cases exhibit contributes to the support of the general blood pressure and the state of the circulation of these patients resembles, to some degree, that which may be found soon after extensive dorso-lumbar sympathectomy.
Those who are more seriously ill seem unable to acquire physiological equilibrium in the upright position by the 2 means mentioned, for they fall back on a third device. The uncontrollable muscular movements in the lower extremities, which these cases show, would prevent the pooling of blood in dependent extremities and assist its return to the heart. It is to be regretted that these movements overwhelm the ballistic records so that there is no direct evidence of their effect upon the general circulation. In my experience, these uncontrollable movements have always occurred before the development of serious symptoms, for persons subject to fainting, when standing on our apparatus, have regularly ruined the record by their movements before collapsing. Exhorting these patients to stand still has had no effect whatever.

It seems evident, therefore, that when a person arises, a series of physiological mechanisms may be drawn upon to support the circulation. In the healthy, vasomotor adjustments suffice and the volume of the circulation is altered but little. But in ill health, the vasomotor regulatory mechanism may be impaired and the reserves must be called upon. Increase of the circulation is one of these ; if this response is impossible or insufficient, muscular movements are added to support it. It is only when these mechanisms fail that the blood pressure falls dangerously and the subject collapses.

The terminal events of this train have been much studied $(10,11)$; there have been fewer data on the early stages of the process $(12,13)$. The clinical condition known as postural hypotension is a rarity, but abnormality of postural responses, as detected by our tests, is an extremely common clinical condition. We suspect that inability to regulate the circulation in the upright position is one reason why persons take to their beds when they are sick.

In the multifarious conditions of disease, it is not to be expected that the reserve mechanisms will always respond in the order mentioned above. An unusually effective vasomotor mechanism may permit a diminished circulation in the upright position; one of our subjects (Figure 3 ) exhibited a reduced circulation when upright, without any symptoms whatsoever. In advanced heart dis- 
ease, increase of circulation may be impossible; in our experience, incoordination downward was encountered most frequently in patients with heart disease.

The "downward" incoordination exhibited by the cases of postural hypotension and hemangioma of the leg was obviously of another type. In the first case, the primary cause may be assigned to the profound abnormality of the vascular reflexes demonstrated in this subpect (7). No similar study was made of the second case but, as the administration of vasoconstrictor drugs was followed by an improvement in her ability to sit upright, we have evidence of vasomotor abnormality in this patient also. In the case of hemangioma, the primary cause was undoubtedly the anatomical abnormality. We agree with the usual view that, in cases such as these, cardiac output diminishes because blood pools in the dependent parts of the body, and venous return is insufficient.

An important practical question must be discussed. In how many of these cases could the postural abnormalities, demonstrated by the ballistocardiograms, have been detected by simpler procedures, such as observation of pulse and blood pressure? Statistical analysis of the results on normal persons (5) allows us to define normal standards for changes in pulse rate and blood pressure when subjects arise. Our results (5) and those of Schneider and Truesdell (14) are almost identical. The statistical normal limits, twice the standard deviation applied to each side of the mean are: for systolic pressure, +15 to -13 $\mathrm{mm} . \mathrm{Hg}$; for diastolic pressure, +22 to -10 $\mathrm{mm} . \mathrm{Hg}$; for pulse rate, +33 to 0 beats per minute. Using these data as a test for normality, if blood pressure alone had been studied, about 80 per cent of our abnormal cases would have been missed. If only pulse rate had been observed, about half of our abnormal cases would have been missed.

Great interest centers in the group of patients who have demonstrable functional abnormalities of the circulation without any known disease to account for them, the group usually diagnosed neurocirculatory asthenia, whose data are shown in the upper right of Figure 2. In previous communications, we showed that about two-thirds of this group exhibited hyper- or hypokinemia (1).
It has now been demonstrated that many of these patients have abnormal responses to arising and some suffer from this abnormality without either hyper- or hypokinemia. Those passing both tests have now been reduced to a few. These few patients, normal to both our tests, may be either imagining their symptoms or unduly conscious of bodily sensations ignored by healthy people.

The abnormalities of the circulation demonstrated in the great majority of these patients with "neurocirculatory asthenia" are not peculiar to this group, and this is in accord with expectations. The widespread occurrence of the symptoms common to this disorder was commented on by $\mathrm{Da}$ Costa, the first writer on this subject (15), and especially emphasized by Lewis, writing in 1940 (16). The latter, after discussing the variety of patients exhibiting symptoms such as undue breathlessness, palpitation, precordial pain, faintness, easy fatigue after exertion, and nervousness wrote (16), "The picture drawn is in many ways a picture without a central motive to fix the attention." Our data suggest that this central motive, the factor common to such cases, is associated with an incoodination of the circulation, i.e., an inability to adapt it to the needs of the moment.

\section{SUMMARY}

The response of the circulation when the subject arose, as determined by the ballistocardiograph, has been employed as a test of its coordination, i.e., of the ability to adapt the cardiac output to the needs of the moment.

Normal standards for circulatory coordination have been determined by a statistical analysis of the results of 120 tests made on 75 healthy young adults, before and after arising. Over 150 patients have been studied also.

In healthy persons, the physiological adjustment necessitated by assuming the erect position is largely accomplished by the vasomotor mechanism and the cardiac output changes but little.

In many sick persons, the circulation changes much more and the abnormality may be in either direction. In the commoner type, the circulation is unduly increased on arising, as if the vasomotor responses were insufficient to support the blood pressure unaided. This type is found with great 
frequency in many types of disease. In the much rarer type, the circulation abnormally diminishes on arising.

Many weakened patients cannot stand without involuntary muscular movements of the lower extremities. Such movements are always called forth in persons subject to fainting before they collapse, and they seemed designed to support the circulation. We regard their presence as evidence of the inadequacy of the vasomotor and other circulatory responses to maintain blood pressure.

Patients with symptoms referable to their circulation without detected organic disease, the group often diagnosed neurocirculatory asthenia, show incoordination of the circulation in a large majority of cases. The frequency of such incoordination in many conditions of disease is suggested as the reason for the wide-spread occurrence of the symptoms these patients exhibit, such as undue breathlessness on exertion, faintness, dizziness, and the like.

\section{BIBLIOGRAPHY}

1. Starr, I., Abnormalities of the amount of the circulation (hyper- and hypokinemia) and their relation to neurocirculatory asthenia and kindred diagnoses. Am. J. M. Sc., 1942, 204, 573.

2. Crampton, C. W., The gravity resisting ability of the circulation. Its measurement and significance. Am. J. M. Sc., 1920, 160, 721.

3. Schneider, E. C., Physiology of Muscular Activity. W. B. Saunders, Philadelphia, 1939.

4. Starr, I., Rawson, A. J., Schroeder, H. A., and Joseph, N. R., Studies on the estimation of cardiac output in man, and of abnormalities in cardiac function, from the heart's recoil and the blood's impacts; the ballistocardiogram. Am. J. Physiol., 1939, 127, 1.

5. Starr, I., and Rawson, A. J., The vertical ballistocardiograph; experiments on the changes in the circulation on arising; with a further study of ballistic theory. Am. J. Physiol., 1941, 134, 403.

6. Starr, I., and Schroeder, H. A., Ballistocardiogram; normal standards, abnormalities commonly found in diseases of the heart and circulation, and their significance. J. Clin. Invest., 1940, 19, 437.

7. Jeffers, W. A., Montgomery, H., and Burton, A. C., Types of orthostatic hypotension and their treatment. Am. J. M. Sc., 1941, 202, 1.

8. Starr, I., and Jonas, L., Supernormal circulation in resting subjects (hyperkinemia), with a study of the relation of kinemic abnormalities to the basal metabolic rate. Arch. Int. Med., 1943, 71, 1.

9. Starr, I., and Jonas, L., Syndrome of subnormal circulation in ambulatory patients. Arch. Int. Med., 1940, 66, 1095.

10. Weiss, S., Wilkins, R. W., and Haynes, F. W., The nature of circulatory collapse induced by sodium nitrite. J. Clin. Invest., 1937, 16, 73.

11. Mayerson, H. S., Roentgenkymographic determination of cardiac output in syncope induced by gravity. Am. J. Physiol., 1943, 138, 630.

12. Starr, I., Jr., and Collins, L. H., Jr., Physiological studies of faintness and syncope. J. Clin. Invest., 1931, 9, 561.

13. Turner, A. H., Newton, M. I., and Haynes, F. W., The circulatory reaction to gravity in healthy young women. Am. J. Physiol., 1930, 94, 507.

14. Schneider, E. C., and Truesdell, D., A statistical study of the pulse rate and the arterial blood pressures in recumbency, standing and after a standard exercise. Am. J. Physiol., 1922, 61, 429.

15. Da Costa, J. M., On irritable heart; a clinical study of a form of functional cardiac disorder and its consequences. Am. J. M. Sc., 1871, 61, 17.

16. Lewis, T., The Soldier's Heart and the Effort Syndrome. Shaw and Sons, London, 1940. 